\title{
A study on social capital in banking industry: A case study of Ghavamin bank
}

\author{
Majid Nazari*
}

Department of Accounting, Islamic Azad University, Kashan Branch, Kashan, Iran

C H R O I C L E A B T RAC T

Article history:

Received October 27, 2012

Received in revised format

28 February 2013

Accepted 2 March 2013

Available online

March 32013

Keywords:

Social capital

Cognitive capital

Relational capital

Structural capital

\begin{abstract}
Social capital plays an important role on developing business units especially in banking industry. The proposed study of this paper performs an empirical investigation on the role of social capital on one of newly established private banks in Iran called Ghavamin. The proposed study designs a questionnaire for measuring the level of social capital in terms of cognitive capital, relational capital and structural capital and distributes it among 30 out 67 employees of one their branches in city of Qom, Iran. The questionnaire has been designed in 5 Likert scale format and three hypotheses of the survey have been examined. There are 61 questions associated with the proposed study, where 19 questions are associated with social capital, 22 questions are related to cognitive capital and 20 questions are devoted to structural capital. Cronbach alphas have been calculated as 0.7807 for structural capital, 0.8669 for cognitive capital and 0.8459 for relational capital. The results statistical test indicate that none of social components was in satisfactory level and the organization must endeavor to establish a better infrastructure in terms of social capital.
\end{abstract}

\section{Introduction}

Social capital plays an important role on business development and building sustainable long-terms growth. There is no doubt that human resources are considered as precious assets for organizations and many well-known firms such as Microsoft, Google, etc. have recognized their success through their founders' dedicated works. Human resources are considered as intangible assets and today, there is no doubt that a business unit without skilled and dedicated human resources would more likely to fail on long term horizon (Kaplan \& Norton, 1992; Kaplan \& Norton, 1992). Organizations must learn in todays' business environment and any interruption in learning could create harmful outcomes (Valaski et al., 2012). Emotional intelligence is another human resource characteristics, which could influence business success, substantially. Saeidipour et al. (2012), for instance, investigated the impact of emotional intelligence on organizational learning staff in an empirical case study of Agriculture Organization in city of Isfahan, Iran and confirmed this effect.




During the past few years, there have been tremendous efforts on any organizations to study social capital on different organizations. Saadi and Pahlavan (2013), for instance, investigated the effect of social capital on knowledge creation in Petrochemical industry. They studied the effect of social capital in terms of three components of cognitive, relational and structural capitals on knowledge creation and confirmed that all three items positively impact knowledge creation, significantly. Ali et al. (2012) performed another investigation on building a linking knowledge management practices and the organizational performance of Pakistan's telecommunication. Social capital plays essential role in education systems as will. Alinajafi et al. (2012), for example, investigated the relationship between social capital and employee participation in Gorgan medical science university and reported that social capital influences positively on building intangible assets within industry. Azma et al. (2012) performed another empirical investigation and considered the application of information technology and its relationship with organizational intelligence.

There are literally different definitions for social capital and According to Lawler et al. (1992) "Social capital is sum of real and potential resources, which exists in communication network among people. Social capital involves increasing of bilateral communications, trust, friendship, and cooperation among people". Social capital is one of the most influential factors in todays' economic. Social capital reflects social relationships in an organization and it could lead to better implementations of physical, financial and humanitarian resources of a business unit. There are literally many evidences, which indicate the social capital could contribute to an increase in cooperation and participation within a firm.

Darvish et al. (2013), in an assignment, studied the impacts of intellectual capital on other components and their effects on organizational learning capability. They reported that that human, relational capitals as well as learning capabilities had positive effect on organizational performance while relational capital positively influenced learning capability and human capital impacted positively on relational capital. Veismoradi et al. (2012), in other assignment, studied the relationship between social capital and the learning organizational in one of Iranian firms and reported that social capital had a meaningful relationship with learning organizational. Shahabi et al. (2012) in an empirical investigation first detected important obstacles for applying organizational intelligence and then ranked them based on analytical hierarchy process. In their survey, structural barriers were considered as the most important factors followed by legal barriers, cultural and executive barriers.

\section{The proposed study}

In this paper, we present an empirical investigation to study the status of social capital in one of newly introduced private banks in Iran called Ghavvamin. This bank used to be working as a credit union for years and recently could receive a permission to work with bank identification. The newly established bank has different branches across the country and plans to develop its operations. The case study of this paper is devoted to one of its branches in city of Qom, Iran where there were approximately 67 employees working there. Therefore, the sample size is calculated as follows,

$$
n=\frac{N \times z_{\alpha / 2}^{2} \times p \times q}{\varepsilon^{2} \times(N-1)+z_{\alpha / 2}^{2} \times p \times q},
$$

where $N$ is the population size, $p=1-q$ represents the yes/no categories, $z_{\alpha / 2}$ is CDF of normal distribution and finally $\varepsilon$ is the error term. Since we have $p=0.5, z_{\alpha / 2}=1.96$ and $N=67$, the number of sample size is calculated as $n=30$. In our survey, all participants were male, 8 people were single and 22 people were married, 16 employees aged 25-30 and 14 of them were older than 30 . In addition, Fig. 1 shows participants educational backgrounds. 


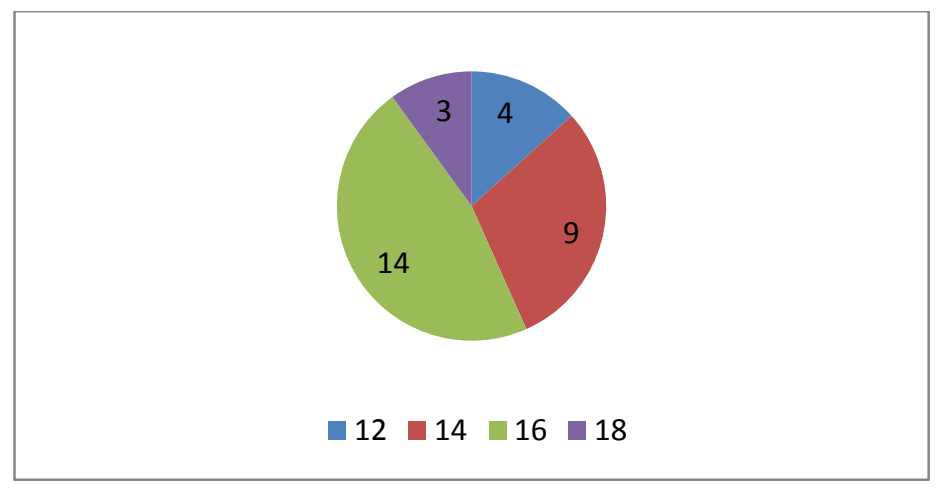

Fig. 1. Frequency of people's educational backgrounds in terms of years of educations

As we can observe from the results of Fig. 1, most employees hold either Bachelor of Science or master's degrees (14 or 16 years of education). Therefore, the participants hold good university educations. The proposed study has one main hypothesis and three sub-hypotheses as follows,

Main hypothesis: Social capital is in good conditions within the organizations.

1. First sub-hypothesis: Bank Ghavvamin maintains good structural capital.

2. First sub-hypothesis: Bank Ghavvamin maintains good cognitive capital.

3. First sub-hypothesis: Bank Ghavvamin maintains good relational capital.

We have designed a questionnaire consists of 61 questions where 19 questions are associated with social capital, 22 questions are related to cognitive capital and 20 questions are devoted to structural capital. Cronbach alphas (Cronbach, 1951) have been calculated as 0.7807 for structural capital, 0.8669 for cognitive capital and 0.8459 for relational capital. These components are within the acceptable limits. All questions are designed in Likert scale from 1 to 5 where one represents completely disagree and 5 represents completely agree. The null $\left(\mathrm{H}_{0}\right)$ and alternative hypothesis $\left(\mathrm{H}_{1}\right)$ are as follows,

$\begin{cases}H_{0}: & \mu \leq 3 \\ H_{1}: & \mu>3\end{cases}$

To test the hypotheses, we use t-student tests and next section presents details of our findings.

\section{The results}

In this section, we present details of our findings on testing three hypotheses of this survey.

\subsection{The first hypothesis: The effect of structural capital}

The first hypothesis considers the condition of structural capital and our survey maintained an average and standard deviation of 3.08595 and 0.41568 , respectively. This yields a t-student of 0.2067 , which is not statistically significant with $\alpha=5 \%$. Therefore, we can accept null hypothesis and conclude that the current banking working condition has not created good circumstances in terms of structural capital.

\subsection{The second hypothesis: The effect of cognitive capital}

The second hypothesis considers the condition of cognitive capital and our survey computed an average and standard deviation of 3.49695 and 0.50431 , respectively. This yields a t-student of 0.985405 , which is not statistically significant with $\alpha=5 \%$. Therefore, we can accept null hypothesis 
and conclude that the current banking working condition has not created good circumstances in terms of cognitive capital.

\subsection{The third hypothesis: The effect of relational capital}

The last hypothesis investigates the condition of relational capital and our study indicated an average and standard deviation of 2.91335 and 0.53205 , respectively. This yields a t-student of -0.1628 , which is not statistically significant with $\alpha=5 \%$. Therefore, we can accept null hypothesis and conclude that the current banking working condition has not created good circumstances in terms of relational capital.

\section{Discussion and conclusion}

In this paper, we have discussed the relative importance of human capital on the success of newly born business units. There is no doubt that any organization needs to have highly skilled, qualified and dedicated people to reach its long-term objectives and social capital plays an important role on the success of organization. The proposed study of this paper has found some alarming results, which could help the officials of this bank to reconsider their current condition and possibly make some necessary changes. This paper can be extended to other research works by considering the effects of intellectual capital on the success of banking industry and we leave it for interested researchers as future study.

\section{References}

Ali, A.M., Qadus, A., Waseem, A., \& Zaman, K. (2012). Linking knowledge management practices and the organizational performance of Pakistan's telecommunication. Management Science Letters, 2(8), 2929-2938.

Alinajafi, Z., Askarinejad, M., Veiseh, S., \& Kamari, F. (2012). The relationship between social capital and employee participation in Gorgan medical science university. Management Science Letters, 2, 819-826.

Azma, F., Mostafapour, M.A., \& Rezaei, H. (2012). The application of information technology and its relationship with organizational intelligence. Procedia Technology, 1, 94-97.

Cronbach, L. J. (1951). Coefficient alpha and the internal structure of tests. Psychometrika, 16(3), 297-334.

Darvish, H., Ahmadi, A.A., Kafashzadeh, A., Farid, S. \& Nejatizadeh, N. (2013). Investigating the effects of intellectual capital on organizational performance measurement through organizational learning capabilities. Management Science Letters, 3, 165-172.

Kaplan, R. S. \& Norton, D. P. (1992). The balanced scorecard - measures that drive performance, Harvard Business Review, 70(1), 71-79. 704

Kaplan, R.S. \& Norton, D.P. (1996). The balanced scorecard: translating strategy into action, Harvard Business School Press, Boston, MA.

Saadi, M.R., \& Pahlavan, N. (2013). The effect of social capital on knowledge creation in Petrochemical Industry. Management Science Letters, 3, 879-884.

Saeidipour, B., Akbari, P., Marati Fashi, M.A. (2012). Study the effect of emotional intelligence on organizational learning staff, Case study: Jihad Agriculture Organization of Isfahan. Management Science Letters, 2(7), 2501-2510.

Shahabi, A., Faez, A., \& Fazli, D. (2012). Organizational intelligence dismounting barriers prioritization: A real-world case study. Management Science Letters, 2, 3013-3022.

Valaski, J., Malucelli, A., \& Reinehr, S. (2012). Ontologies application in organizational learning: A literature review Article. Expert Systems with Applications, 39(8), 7555-7561.

Veismoradi, A., Akbari, P., \& Rostami, R. (2012). A study on the effect of social capital on learning organization: A case study of Jihad Agriculture Organization of Kermanshah, Iran. Management Science Letters, 2(8), 2909-2916. 